\title{
BASAL GASTRIC SECRETION AS A CLINICAL TEST OF GASTRIC FUNCTION WITH SPECIAL REFERENCE TO PEPTIC ULCER
}

\author{
By ARTHUR L. BLOOMFIELD, CHEN KUO CHEN, AND LINDOL R. FRENCH \\ (From the Department of Medicine, Stanford University School of Medicine, San Francisco) 1
}

(Received for publication June 7, 1940)

The use of gastric analysis as a diagnostic method has in recent years fallen under a cloud and, while descriptions of new modifications of test meals continue to appear, they receive at best a half-hearted reception. The reason for this is not far to seek. Variations in gastric secretion are so wide in healthy people that very little specific diagnostic information can be elicited in disease. It is true, to be sure, that many patients with duodenal ulcer have a highly acid gastric juice but the limit attained by the normal stomach after the conventional stimuli is not transcended (1). All one can say is that high acid is compatible with duodenal ulcer but not diagnostic. Very low acid or anacidity is strong evidence against duodenal ulcer, and this is perhaps the most valuable piece of clinical information to be obtained from gastric analysis. The anacidity which used to be thought so suggestive of cancer is now known to occur in many healthy elderly people (2); and the presence of acid even in large amounts by no means rules out neoplasms, especially those forms originating in a peptic ulcer (3).

It occurred to us that potential differences in gastric secretion might be wiped out by powerful stimuli such as histamine which are in vogue in the clinic, and going a step farther we wondered whether measurements of the spontaneous gastric secretion obtained without the use of any stimulus might in disease show significant deviations from the normal and hence be useful in clinical diagnosis.

\section{LITERATURE}

Pavlov (4), working with dogs, found that in the interdigestive period no true gastric juice was secreted and that the reaction of the mucosa became alkaline. Beaumont years before had made similar observations in the case of his famous subject St. Martin. Carlson (5), on the other hand, pointed out that a continuous gastric

\footnotetext{
1 Supported by a grant from the Rockefeller Foundation.
}

secretion occurred in some normal people and concluded that "complete rest of the gastric glands is an exceptional state in the healthy individual." These two views have led to a good deal of controversy and the subject is well analyzed in a recent paper by Pavlov's pupil Babkin (6). Much of the discussion has been of a quibbling sort, the advocates of the Pavlov position holding that any secretion of the apparently resting stomach is in fact due to unrecognized psychic influences or humoral stimuli from food in the intestines, and so forth. It is just because of the very fact that fasting secretion in different people represents the play of humoral and autonomic influences in the individual that its measurement may be of value in human pathology. Lim (7) and his associates made a systematic investigation of basal secretion in the dog. They found, among other things, that secretion continued after all extrinsic nervous connections to the stomach had been severed. However, a great reduction to a low constant level followed section of the vagi; this suggested that reflex stimulation of gastric juice is mediated through these nerves. Nechoroschew (8), again with dogs, confirmed Pavlov's findings of intermittent secretion, but Krimberg (9) found a continuous secretion which he thought was kept up by a stimulating substance secreted by the juice itself. Roberts (10) made an extensive study of basal secretion in man. He pointed out that in a good many people there occurred at the end of an hour or so a sudden decrease of the "spontaneous" gastric juice to a very low level. He regarded basal secretion as due to a combination of "psychic" and "chemical" stimuli. Vandorfy (11), too, found continuous secretion in man to be the rule and believes it to be a "physiological" process modified by psychic influences. There is a considerable literature on continuous gastric secretion during nocturnal sleep (12). All observers agree that during the hours of heavy sleep secretion is practically in abeyance in normal people but Henning and Norpoth (13) found that free secretion continued through the night in duodenal ulcer cases. Secretion was also present in patients with "gastritis" and "neurosis." Winkelstein (14) confirmed these findings. Many years ago Galambos (15) proposed the measurement of basal secretion as a clinical test of gastric function but his data were limited and seem to have attracted no attention.

Whatever the proper physiological interpretation of the views summarized above may turn out to be, it seems established that many people have a continuous secretion of gastric juice. This juice-" secreted by the stomach in the absence of all intentional and avoidable stimulation" ( $\mathrm{Lim}$ )-represents the effect of nervous and 
humoral influences which are characteristic for the individual as we showed in a previous paper (16) where it was pointed out that repeated measurements of basal secretion in the same person under uniform conditions gave practically identical results. For these very reasons measurements of basal gastric secretion would seem useful in the clinical study of patients.

\section{METHODS}

The technique of measuring basal gastric secretion has been described in our previous papers (16). Briefly, the patient is at rest in bed overnight in the hospital and in the morning he is prepared as for a metabolism test. Without the use of any meal or stimulus a small tube is passed into the stomach and the fasting contents are withdrawn. Continuous aspiration is then kept up and the secretions are collected over successive ten-minute periods. Within forty minutes to an hour the stomach usually is found to be secreting at an approximately constant level and the acidity and the ten-minute secretory volume at this point are taken to represent the "basal secretion."

The question, of course, comes up as to whether the passage of the tube modifies true spontaneous gastric secretion, and this question, too, has received consideration in the literature, although no definite conclusion has been reached. There is evidence that gastric distention may stimulate a flow of juice (17); in other experiments it has been suggested that stimulation of the pharynx by the stomach tube reflexly provokes gastric secretion (18).

Our own observations indicate that passage of the tube may have a temporary stimulating or inhibiting effect in different people (or indeed no noticeable effect at all), as illustrated by the protocols in Tables I to V. Certainly no rule can be laid down. We also pointed out, as mentioned above, that repeated examinations of the same individual yielded a highly constant basal

TABLE I

Basal secretion (Case 93-normal)

\begin{tabular}{c|c|c|c}
\hline $\begin{array}{c}\text { Ten-minute } \\
\text { period } \\
\text { number }\end{array}$ & $\begin{array}{c}\text { Ten-minute } \\
\text { volume of } \\
\text { secretion }\end{array}$ & $\begin{array}{c}\text { Free } \\
\text { hydrochloric } \\
\text { acid }\end{array}$ & Total acid \\
\cline { 2 - 2 } & $c c$. & & \\
Fasting & 5 & 52 & 67 \\
1 & 3 & 58 & 72 \\
2 & 7 & 94 & 104 \\
3 & 6 & 102 & 113 \\
4 & 3 & 96 & 115 \\
5 & 6 & 70 & 85 \\
$* 6$ & 8 & 73 & 88 \\
\hline
\end{tabular}

* The values for volume of secretion and total acid in this period are taken as "basal secretion."
Comment: After the small amount of fasting contents was removed, there seemed to be a transient inhibition of acid in period 1 followed by stimulation in periods 2 to 4 . Finally a basal level was reached in periods 5 and 6 . Note low volumes of secretion throughout in contrast to high basal acidity.

TABLE II

Basal secretion (Case 88-normal)

\begin{tabular}{c|c|c|c}
\hline \hline $\begin{array}{c}\text { Ten-minute } \\
\text { period } \\
\text { number }\end{array}$ & $\begin{array}{c}\text { Ten-minute } \\
\text { volume of } \\
\text { secretion }\end{array}$ & $\begin{array}{c}\text { Free } \\
\text { hydrochloric } \\
\text { acid }\end{array}$ & Total acid \\
\cline { 2 - 3 } Fasting & $c c$. & & \\
1 & 9 & 3 & 5 \\
2 & 7 & 3 & 35 \\
3 & 9 & 31 & 63 \\
4 & 7 & 22 & 48 \\
5 & 7 & 10 & 35 \\
$* 6$ & 9 & 0 & 17 \\
& 6 & 0 & 15 \\
\hline
\end{tabular}

* Basal secretion.

Comment: After removal of fasting contents there seemed to be a transient stimulation of acid (periods 2 to 3 ) which then subsided to a basal level (period 6) with no free acid.

TABLE III

Basal secretion (Case 105-normal)

\begin{tabular}{c|c|c|c}
\hline \hline $\begin{array}{c}\text { Ten-minute } \\
\text { period } \\
\text { number }\end{array}$ & $\begin{array}{c}\text { Ten-minute } \\
\text { volume of } \\
\text { secretion }\end{array}$ & $\begin{array}{c}\text { Free } \\
\text { hydrochloric } \\
\text { acid }\end{array}$ & Total acid \\
\cline { 2 - 4 } Fasting & $c c$. & & \\
1 & 30 & 0 & 8 \\
2 & 8 & 0 & 6 \\
3 & 4 & 0 & 6 \\
4 & 7 & 0 & 10 \\
5 & 10 & 0 & 10 \\
$* 6$ & 4 & 0 & 13 \\
7 & 5 & 10 & 35 \\
8 & 12 & 12 & 40 \\
9 & 23 & 63 & 72 \\
* Histamine & 72 & 86 \\
\hline Basal secretion. & 20 & &
\end{tabular}

Comment: During the first few periods secretion seems to be inhibited. A small amount of acid subsequently is secreted (periods 5 to 6 ) but the volume of secretion is unchanged. After histamine there is a free flow of quite acid juice. Contrast this case with the preceding (Table II). 
TABLE IV

Basal secretion (Case 95-normal)

\begin{tabular}{c|c|c|c}
\hline \hline $\begin{array}{c}\text { Ten-minute } \\
\text { period } \\
\text { number }\end{array}$ & $\begin{array}{c}\text { Ten-minute } \\
\text { volume of } \\
\text { secretion }\end{array}$ & $\begin{array}{c}\text { Free } \\
\text { hydrochloric } \\
\text { acid }\end{array}$ & Total acid \\
\cline { 2 - 3 } Fasting & $c c$. & & \\
1 & 45 & 0 & 4 \\
2 & 10 & 8 & 27 \\
3 & 22 & 5 & 21 \\
4 & 18 & 17 & 37 \\
5 & 15 & 35 & 56 \\
6 & 7 & 35 & 60 \\
$* 7$ & 8 & 29 & 56 \\
& 7 & 35 & 65 \\
\hline
\end{tabular}

* Basal secretion.

Comment: The fasting contents are often large in volume and low in acid due to admixture of saliva, duodenal contents, etc. In successive tenminute periods there was first a free flow of juice of low acidity. During succeeding periods the volume of juice fell but the acid increased, reaching a basal level 7 to $8 \mathrm{cc}$. per ten minutes with an acidity of approximately 60 .

TABLE $v$

Basal secretion (Case 106-normal)

\begin{tabular}{c|c|c|c}
\hline \hline $\begin{array}{c}\text { Ten-minute } \\
\text { period } \\
\text { number }\end{array}$ & $\begin{array}{c}\text { Ten-minute } \\
\text { volume of } \\
\text { secretion }\end{array}$ & $\begin{array}{c}\text { Free } \\
\text { hydrochloric } \\
\text { acid }\end{array}$ & Total acid \\
\hline & cc. & & \\
Fasting & 60 & 44 & 60 \\
1 & 8 & 44 & 60 \\
2 & 5 & 34 & 58 \\
3 & 6 & 29 & 58 \\
4 & 6 & 38 & 67 \\
5 & 5 & 38 & 67 \\
$* 6$ & 5 & 38 & 67 \\
\hline
\end{tabular}

* Basal secretion.

Comment: In this case there seemed to be neither stimulation nor inhibition by passage of the tube. There is a steady practically uniform secretion from the start.

secretion and apparently pictured a certain type of stomach and autonomic organization.

Comparison of basal secretion with that obtained after histamine is of interest. Figure 1 shows a series of values for basal acidity in normal people and also the acidity attained in the same individuals after histamine stimulation. In almost all cases the acid was swept up to a high value and differences were much less clearly brought out than by the basal acidity.

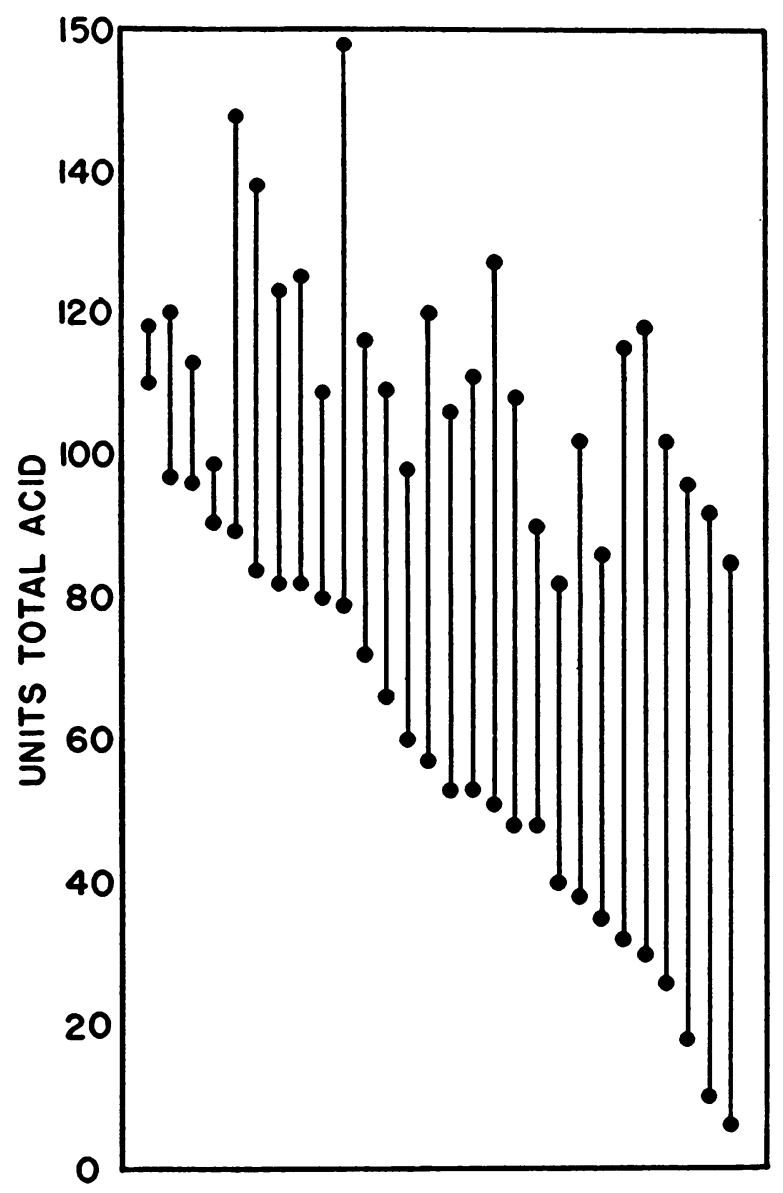

Fig. 1. Comparison of Basal Gastric Acidity and Acidity After Histamine

Lower dots = basal acidity; upper dots = level attained after standard dose of histamine in same individuals.

\section{Basal secretion in controls}

In Figure 2 each solid black dot represents the total basal acidity in a different case, as measured by titration with phenolthalein in the usual way. The patients were a miscellaneous hospital group, none with serious disease and none as far as we could tell with any disease of the gastro-intestinal tract. They serve as controls with which to compare the findings in peptic ulcer and other gastric disorders. Fourteen of these subjects had no free acid in the basal secretion but no patient is included who did not put out acid in response to histamine. No attempt was made in this small series to treat males and females separately but the values are plotted in relation to age. Points of note are the wide variations in basal acidity in 


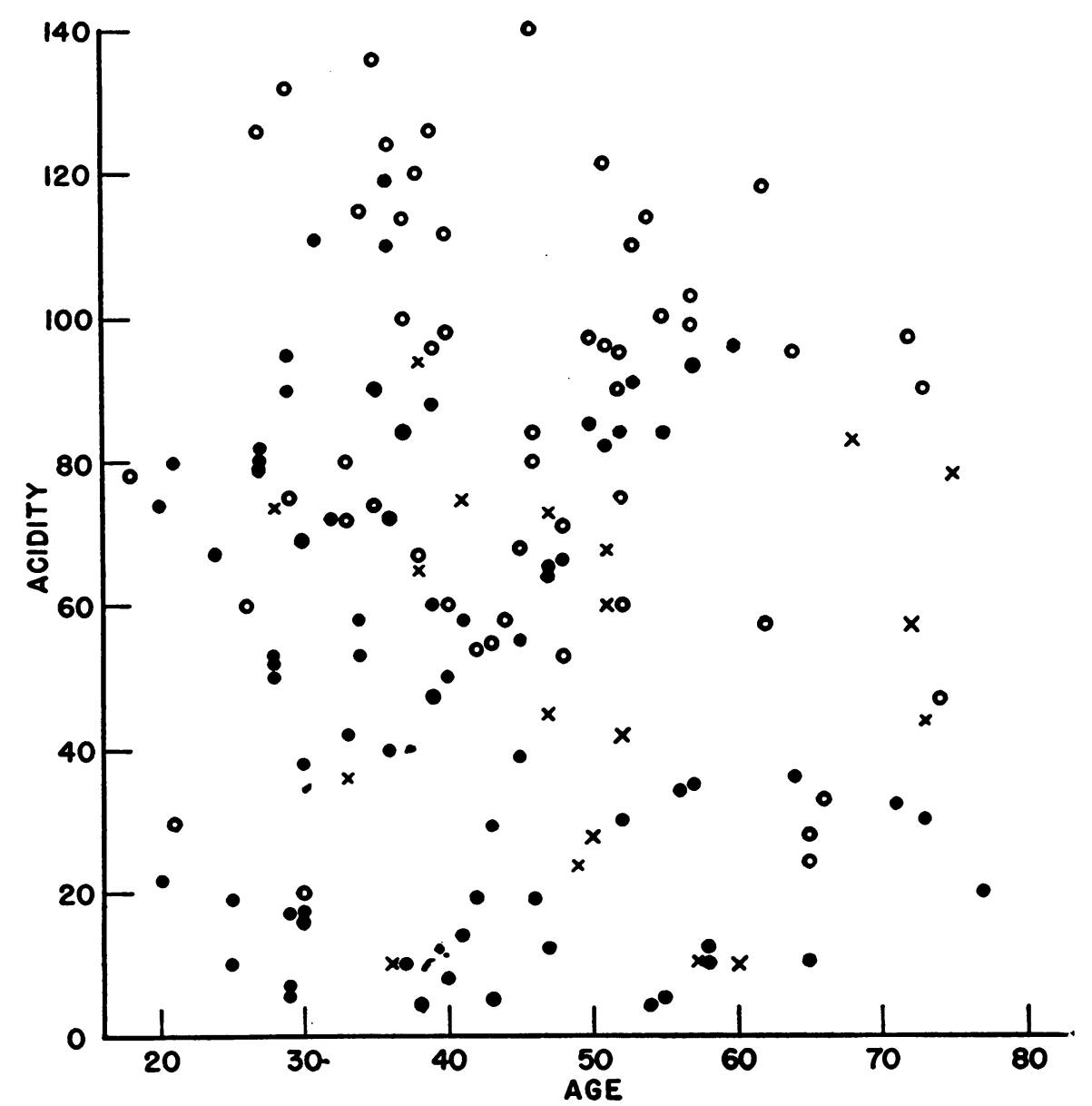

Fig. 2. Basal Gastric Acidity in Relation to Age

Solid dots $=$ controls; circles $=$ duodenal ulcer cases; crosses $=$ gastric ulcer cases.

different people and the fact that basal acidity may be as high as 100 or more. As with histamine secretion (19) a decrease in acidity with advancing years is evident, the average total acidity for the three age groups of below 40,40 to 60 , and above 60 being 56.5, 47.6 and 26 .

\section{Basal secretion in peptic ulcer}

Basal secretion was measured in 71 cases of peptic ulcer-52 duodenal, 19 gastric. We considered the diagnosis to be definite in all these patients on the basis of unequivocal $x$-ray findings, operation or gastroscopy. In Figure 2, each circle represents the basal acidity in a case of duodenal ulcer; each cross stands for a gastric ulcer. The high values with duodenal ulcer are immediately apparent but the important point is that in this disease basal acidity is often above the uppermost level reached in the control series; its measurement may therefore have some real diagnostic value. This is brought out more clearly in Figure 3. The upper columns constructed from the data of Polland (20) show the distribution of various grades of acidity in controls and in duodenal ulcer cases after histamine. While most of the ulcer cases have high acidity, the levels reached by controls are not exceeded; hence high acid after histamine proves nothing. Turning to the lower columns which picture basal secretion, it is seen that a considerable number of ulcer cases fall entirely outside the zone reached by the controls. Of the 3 controls with acid of over 100, 2 complained of indigestion and, even though $\mathrm{x}$-rays showed nothing abnormal, they may have had ulceration in the past. It appears, then, that a basal acidity of over 100 is 


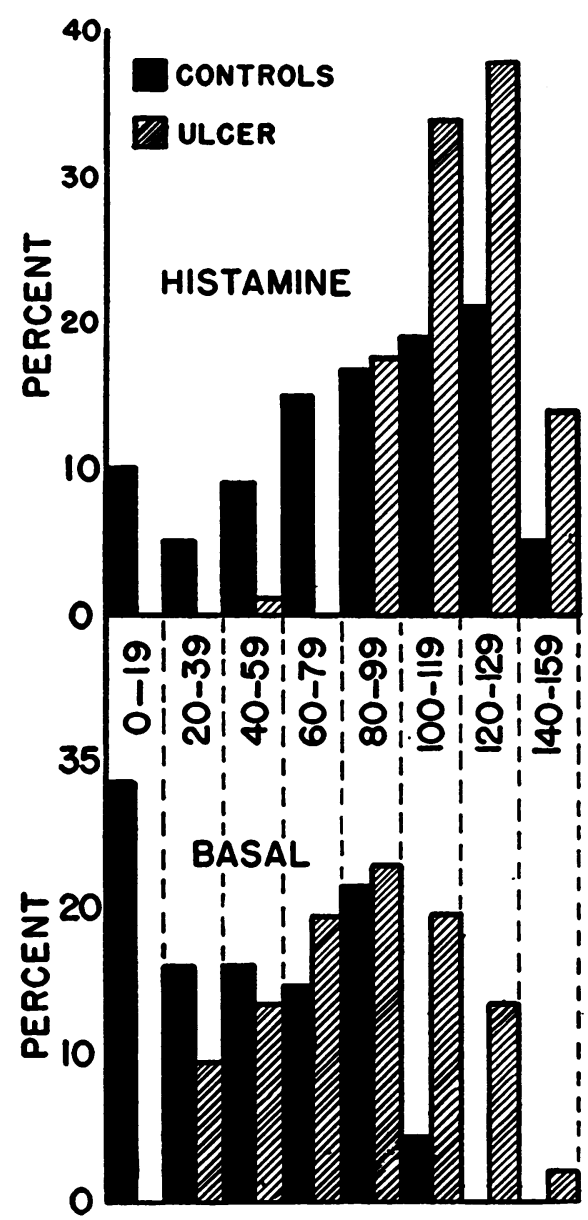

Fig. 3. Distribution Curves of Total Gastric Acidity in Controls and Ulcer Cases

Upper columns $=$ after histamine; lower columns $=$ basal secretion.

almost positive evidence of duodenal ulcer, and basal acidity of over 120 makes the diagnosis quite definite.

The gastric ulcer cases are not numerous enough to treat statistically but a glance at Figure 2 shows them scattered through the normal zone. The basal acid values varied from 0 to 96 . This difference in basal acidity of duodenal and gastric ulcer cases suggests, as many believe, that the two diseases are fundamentally different and should not be considered as one group.

In Figure 4 not only acidity but also rate of secretion is taken into account by multiplying the total acidity by the volume (cc.) of basal secretion during the ten-minute test period. The values so obtained in each case are plotted against age, using the same symbols as in Figure 2 .
Here again the outstandingly high values in duodenal ulcer are noted.

\section{DISCUSSION}

In a previous paper (21) the errors inherent in test-meals such as the Ewald meal were pointed out. We now add a criticism of the histamine test. This powerful stimulus tends to sweep gastric secretion up to high values in a large proportion of people so that differences which might be of diagnostic value are wiped out. The present study shows the wide variation of basal secretion in controls but emphasizes that in many patients with duodenal ulcer basal secretion reaches higher values than are ever attained by people with normal stomachs. Hence very high basal secretion seems to have real diagnostic value when duodenal ulcer is under suspicion. Indeed this measurement may give information not to be gained by $\mathrm{x}$-ray study or by gastroscopy, since excessively high basal acid values probably mark the individuals who are likely to have duodenal ulceration from time to time, even though no break in the mucosa may be demonstrable at the moment of any single examination. In other words, if there is any type of diathesis predisposing to duodenal ulcer, as emphasized-we believe correctly-by Hurst (22) and others, abnormally high basal secretion is probably the most reliable indicator of such a tendency. That excessively high gastric acidity is the result of ulcer is an old view now thoroughly discredited by studies which show that the secretion remains essentially unchanged after the ulcer has healed.

If studies of gastric juice are to be made at all for clinical purposes, the simplest and most informative procedure seems to be a measurement of the basal secretion as described above. All the apparatus necessary is the stomach tube and syringe; no meal is given, no powerful and perhaps toxic drug is injected. If, with the basal test, no acid is secreted, then histamine may be given to rule out true anacidity. It is to be hoped that definitive normal standards of basal secretion will be established by careful examination of large groups of healthy people.

\section{SUM MARY}

1. Basal gastric secretion was measured in a series of 70 controls by a standard technique. 


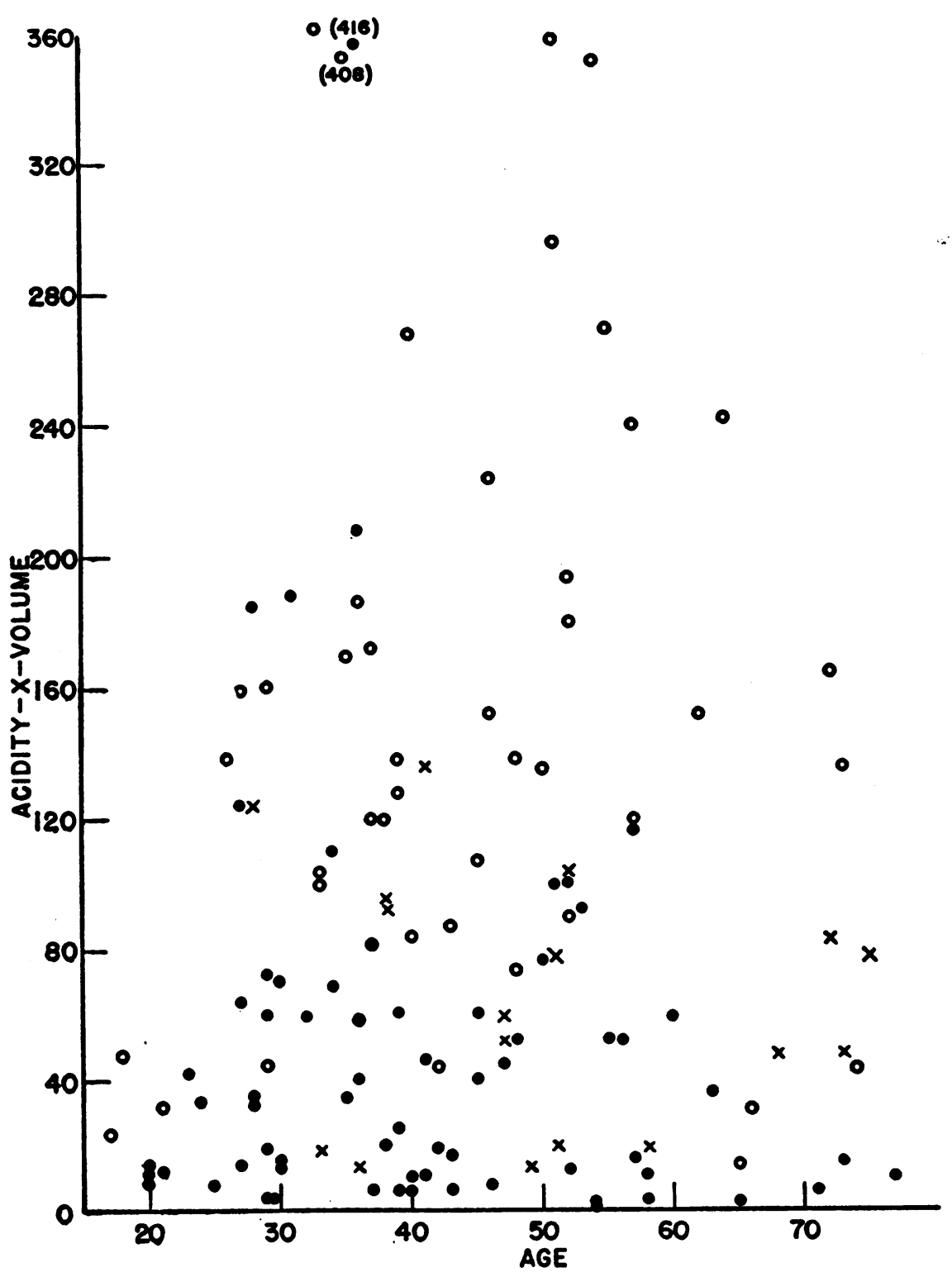

Fig. 4. Rate of Basal Secretion

Same designations as in Figure 2.

The wide variations in different people, which are to a large extent wiped out by histamine stimulation, are described.

2. Similar measurements in a series of patients with peptic ulcer show that basal acidity with duodenal ulcer often exceeds the highest control values; hence this measurement has definite diagnostic value.

3. Values for basal acidity in gastric ulcer cases are similar to the controls and suggest that gastric and duodenal ulcer are fundamentally different disorders.

4. Measurement of basal secretion is suggested as the simplest and most useful procedure in the study of clinical gastric physiology. If basal anacidity exists the test should be supplemented by histamine stimulation. 


\section{BIBLIOGRAPHY}

1. Bloomfield, A. L., Clinical aspects of gastric secretion. Ann. Int. Med., 1932, 6, 307.

2. Polland, W. S., and Bloomfield, A. L., Unexplained gastric anacidity. Arch. Int. Med., 1931, 48, 412.

3. Bloomfield, A. L., The diagnosis of early cancerous changes in peptic ulcer. J. A. M. A., 1935, 104, 1197.

4. Pavlov, I. P., The Work of the Digestive Glands, Lippincott, London, 1910.

5. Carlson, A. J., Secretion of gastric juice in health and disease. Physiological Rev., 1923, 3, 1.

6. Babkin, B. P., Does the stomach secrete gastric juice continuously? Libman Anniv. Vols., 1932, 1, 113.

7. Loo, C. T., Chang, H. C., and Lim, R. K. S., The basal secretion of the stomach. I. Influence of residues in small and large intestine. Chinese $\mathrm{J}$. Physiol., 1928, 2, 259.

Hou, H. C., and Lim, R. K. S., The basal secretion of the stomach. II. Influence of nerves and the question of secretory "tone" and reactivity. Ibid., $1929,3,41$.

Lim, R. K. S., et al., The basal secretion of the stomach. III. Influence of feeding bone and other hard objects. Ibid., 1930, 4, 1.

Chang, H. C., and Lim, R. K. S., The basal secretion of the stomach. IV. Influence of mechanical irritation of the pyloric region. Ibid., 1931, 5, 233.

8. Nechoroschew, N. P., Saure Magensekretion und periodische Tätigkeit des Verdauungskanals bei nüchternen Hunden. Ztschr. f. d. ges. exper. Med., 1929, 69, 64.

9. Krimberg, E., Uber die autosekretorische Eigenschaft des Magensaftes. Arch. f. d. ges. Physiol., 1931, 226, 816.

10. Roberts, W. M., The fasting gastric secretion in man. Quart. J. Med., 1927, 21, 7.

11. Vandorfy, J., Studien über die interdigestive Phase des Magens beim Menschen. II. Die Nüchternsekretion. Arch. f. Verdauungskr., 1927, 40, 364.

12. Chalfen, S. S., Die Sekretion des Magens während der Nacht. Arch. f. Verdauungskr., 1930, 47, 106.
13. Henning, N., and Norpoth, L., Untersuchung über die sekretorische Funktion des Magens während des nächtliches Schlafes. Die Magensekretion während des Schlafes. Deut. Arch. f. Klin. Med., 1932, 172, 559, also Arch. f. Verdauungskr., 1933, $53,64$.

14. Winkelstein, A., One hundred and sixty-nine studies in gastric secretion during the night. Am. J. Digest. Dis. and Nutrition, 1935, 1, 778.

15. Galambos, A., Direct examination of the gastric juice; new functional test. Arch. Int. Med., 1926. 38, 654.

16. Polland, W. S., and Bloomfield, A. L., Basal gastric secretion in man. Bull. Johns Hopkins Hosp., 1931, 49, 302.

17. Hardy, H. H., and Quanstran, V. E., Effect of gastric distension on gastric secretion. Proc. Soc. Exp. Biol. and Med., 1937, 37, 28.

Raine, F., and Perry, M. C., Intestinal obstruction. Experimental studies on toxicity, intra-intestinal pressure, and chloride therapy. Arch. Surg., 1929, $19,478$.

18. Garin, C., et al., Sécrétion gastrique provoquée par simple présence d'une sonde d'Einhorn dans les voies digestives. L'excitation qui déclanche le reflexe sécrétoire parait se produire au niveau du pharynx. Bull. et mém. Soc. méd. d'hôp. de Paris, 1929, 53, 984.

19. Bloomfield, A. L., The decrease of gastric secretion with advancing years: further observations. J. Clin. Invest., 1940, 19, 61.

20. Polland, W. S., Histamine test meals; analysis of 988 consecutive tests. Arch. Int. Med., 1933, 51, 903.

21. Bloomfield, A. L., and Keefer, C. S., The rate of gastric secretion in man. J. Clin. Invest., 1927, 4, 485.

22. Hurst, A. F., "Hypersthenic gastric diathesis" and the pathology, prophylaxis, and treatment of duodenal ulcer. Lancet, 1922, 2, 1369. 